\title{
INFLUENCE OF SAMPLING INTERVAL ON DEFLECTION-INFLUENCE-LINE-BASED DAMAGE DETECTION IN BEAMS
}

\author{
Dr Ivana Štimac Grandić* \\ Faculty of Civil Engineering, University of Rijeka, Rijeka, Croatia
}

In this paper, the influence of sampling interval on reliability of damage detection and damage localization based on comparison of deflection influence lines and their derives (slope and curvature) for intact and damaged state is investigated. The numerical analysis is conducted on a simply supported beam with one damaged section for different sampling interval and different position of sampling points to damaged section.

Key words: Damage detection, Beam, Deflection influence line, Sampling interval

\section{INTRODUCTION}

As it is known, non-destructive techniques for damage detection (existence, localization and estimation of damage) are frequently used in the past few decades. Both, methods established on changes in dynamic, as well as in static responses between two states of structure are developed. Also, some researchers combine these two methods. Static methods were used less than dynamic ones but main advantage of static methods over dynamics that there is no need for dynamic characteristic of structure (mass and damping). Hence, the static methods need less complicated calculation algorithms.

One of the static method is based on comparison of deflection influence lines or their derives (slope and curvature of deflection influence lines) for non-damaged and damaged structure. This method can be successfully used for damage localization [01].

Generally, the influence line graph presents the variation of a function (such as deflection) at a specific point on a structure caused by a unit or any non-unit load load placed at any point along the structure. The position of discrete values of deflection influence line are determined by different load positions where each load position represent one sampling point. It is difficult to expect a large number of sampling points during on-site testing therefore it is necessary to determine the influence of sampling interval to reliability of damage detection and damage localization.

\section{DESCRIPTION OF DAMAGE DETECTION METHOD}

In general, structural damage cause changes of the structural response in comparison to the response of non-damaged structure. Structural damage may be defined as any deviation of material or geometric property of the structure (i.e. deviation of structural stiffness).

Let us assume that there is two sets of data collected on structure in different time. By comparing this two sets of data it is possible to get information about changes in response of the structure. If this two data sets are similar, there is no changes in the structural stiffness.

If the structure is damaged, the deflection influence line of non-damaged structure $\eta_{w}(x)=w(x)$ is different form the deflection influence line of damaged structure $\overline{\eta_{w}}(x)=\bar{w}(x)$. Also, the slope and curvature of deflection influence lines for these two states will be different too. The slope of deflection influence line for nondamaged and damaged structure is presented by equations ( $1 a$ and $1 b$ ), and the curvature of deflection influence line for non-damaged and damaged structure is presented by equations (2a and $2 b)$ :

$$
\begin{array}{ll}
\phi(x)=\frac{d w(x)}{d x} ; \quad \bar{\phi}(x)=\frac{d \bar{w}(x)}{d x} \\
\rho(x)=\frac{d w^{2}(x)}{d x^{2}} ; \quad \bar{\rho}(x)=\frac{d w^{2}(x)}{d x^{2}}
\end{array}
$$


Subtracting the deflection influence lines or their slope or curvature gives the information about damage:

I. $R(x)=\bar{w}(x)-w(x)$ the maximum difference in the deflection influence lines point at the location of the damage [02-06];

II. $R_{x}(x)=\bar{\phi}(x)-\phi(x)$ the location of the damage is represented by vertical jump in the difference in the slope of the deflection influence lines [02-05];

III. $R_{x x}(x)=\bar{\rho}(x)-\rho(x)$ the location of the damage is represented vertical peak in the difference in the curvature of the deflection influence lines [02-05, 07].

\section{NUMERICAL ANALYSIS}

The analysis has been carried out for simply supported beam. The span length of the beam is $L=25 \mathrm{~m}$. The cross section area of the beam is $A=0.8567 \mathrm{~m}^{2}$, the moment of inertia is $I=0.14 \mathrm{~m}^{4}$ and Young's modulus is $\mathrm{E}=3.5 \cdot 107 \mathrm{kN} / \mathrm{m}^{2}$. The applied force is $\mathrm{F}=100 \mathrm{kN}$. The numerical model has 100 beam finite elements and 101 finite element nodes (numbered from 0 to 100). The length of each finite element is $\Delta x=0,25 \mathrm{~m}$.

The displacement influence lines have been computed for point in the middle of the span for both the non-damaged and the damaged beam. The damage has been simulated by reducing the bending stiffness of 29th and 30th finite elements by $20 \%$. The damage is situated between 7 and $7,5 \mathrm{~m}$ from left support (Figure 1).
The slope and the curvature of the displacement influence lines have been calculated using finite difference method according to equations ( $3 a$. $3 b 4 a$ and $4 b)$ :

$$
\left(\frac{d w}{d x}\right)_{i}=\frac{w_{i+1}-w_{i-1}}{2 \Delta x} ; \quad\left(\frac{d \bar{w}}{d x}\right)_{i}=\frac{\bar{w}_{i+1}^{(3 a)} \bar{w}_{i-1}}{2 \Delta x}
$$

$\left(\frac{d^{2} w}{d x^{2}}\right)_{i}=\frac{w_{i-1}-2 \cdot w_{i}+w_{i+1}}{\Delta x^{2}} ;\left(\frac{d^{2} \bar{w}}{d x^{2}}\right)_{i}=\frac{\bar{w}_{i-1}-2 \cdot \bar{w}_{i}+\bar{w}_{i+1}}{\Delta x^{2}}$

The four sets of deflection influence lines for nondamaged and damaged beam were calculated. In the first set the sampling interval is $d_{s}=0,25 \mathrm{~m}$; in the second set is $d_{s}=0,75 \mathrm{~m}$; in the third set is $\mathrm{ds}=1,25$; in the fourth is $\mathrm{ds}=2,5 \mathrm{~m}$.

On Figures 2-4, there are shown the differences in the deflection influence lines, the differences in the slope of the deflection influence lines and the differences in the curvature of the deflection influence lines for different sampling intervals ds. As it can be seen, the damage detection is successful regardless of sampling interval. The differences in the deflection influence lines in all analysed cases point at the position of $7,5 \mathrm{~m}$ as potential point of damage (Figure 2). A potential damage section can be estimated by using the difference in the slope/curvature of the deflection influence lines; in cases where simulated damaged section is narrower than the sampling interval (Figures 3 and 4 ) the detected damaged section is wider than it is simulated.

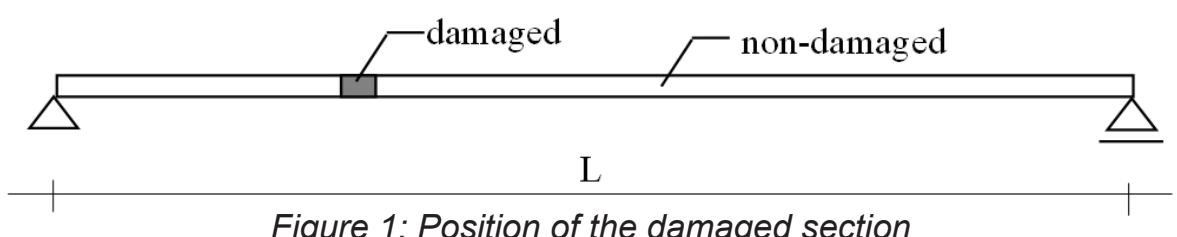



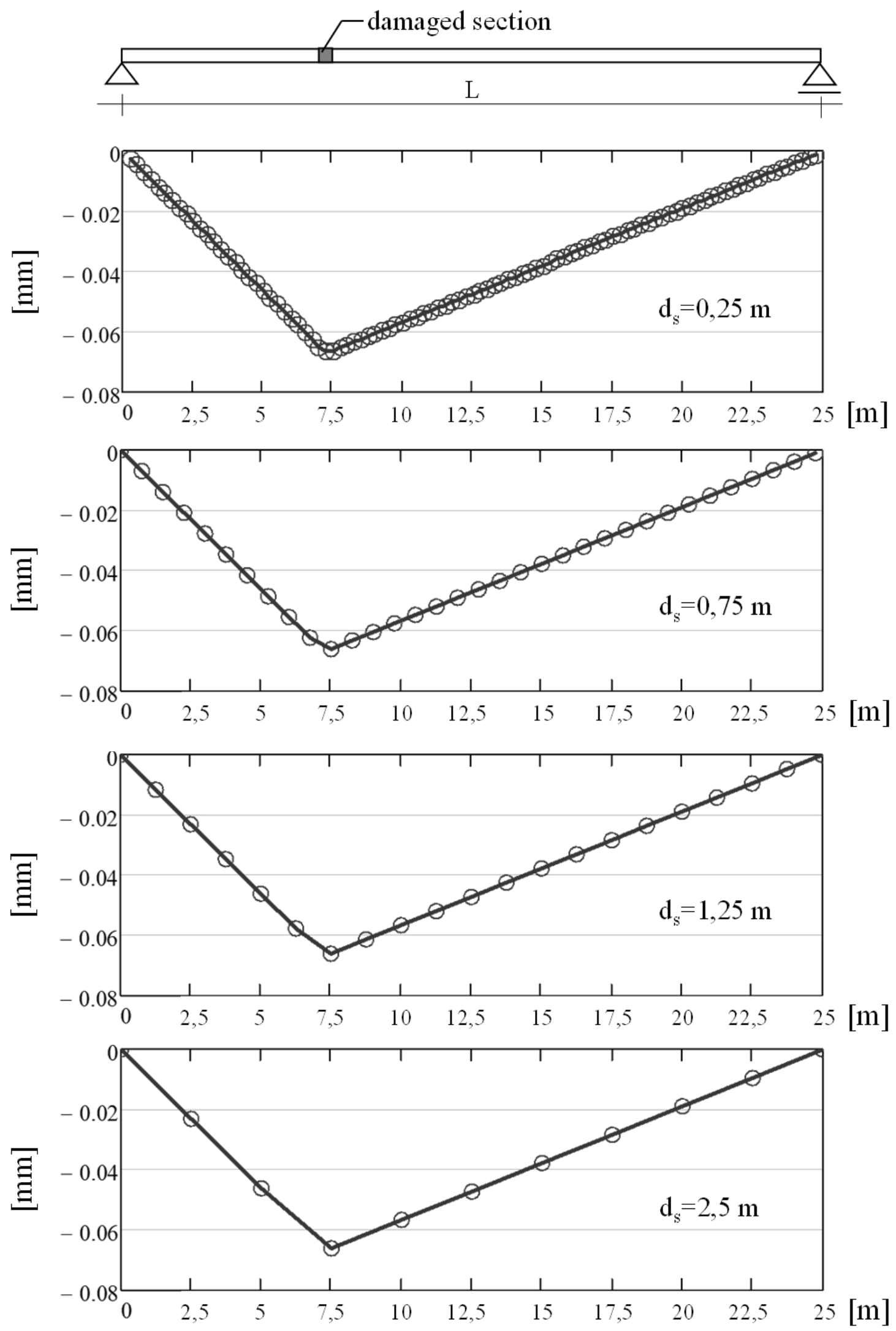

Figure 2: The difference in the deflection influence lines for different sampling interval $d_{s}$ 

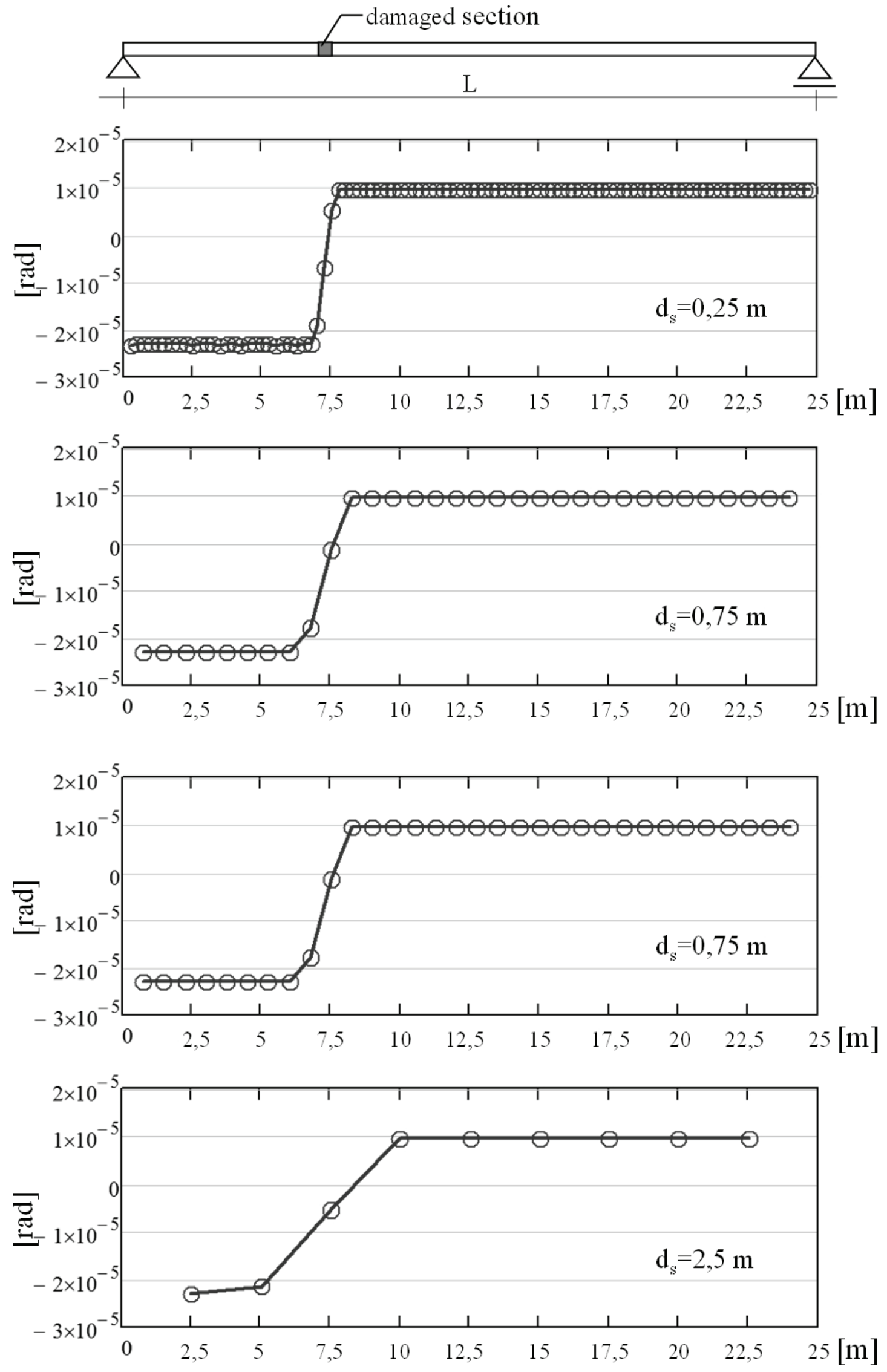

Figure 3: The difference in the slope of the deflection influence lines for different sampling interval $d_{s}$ 

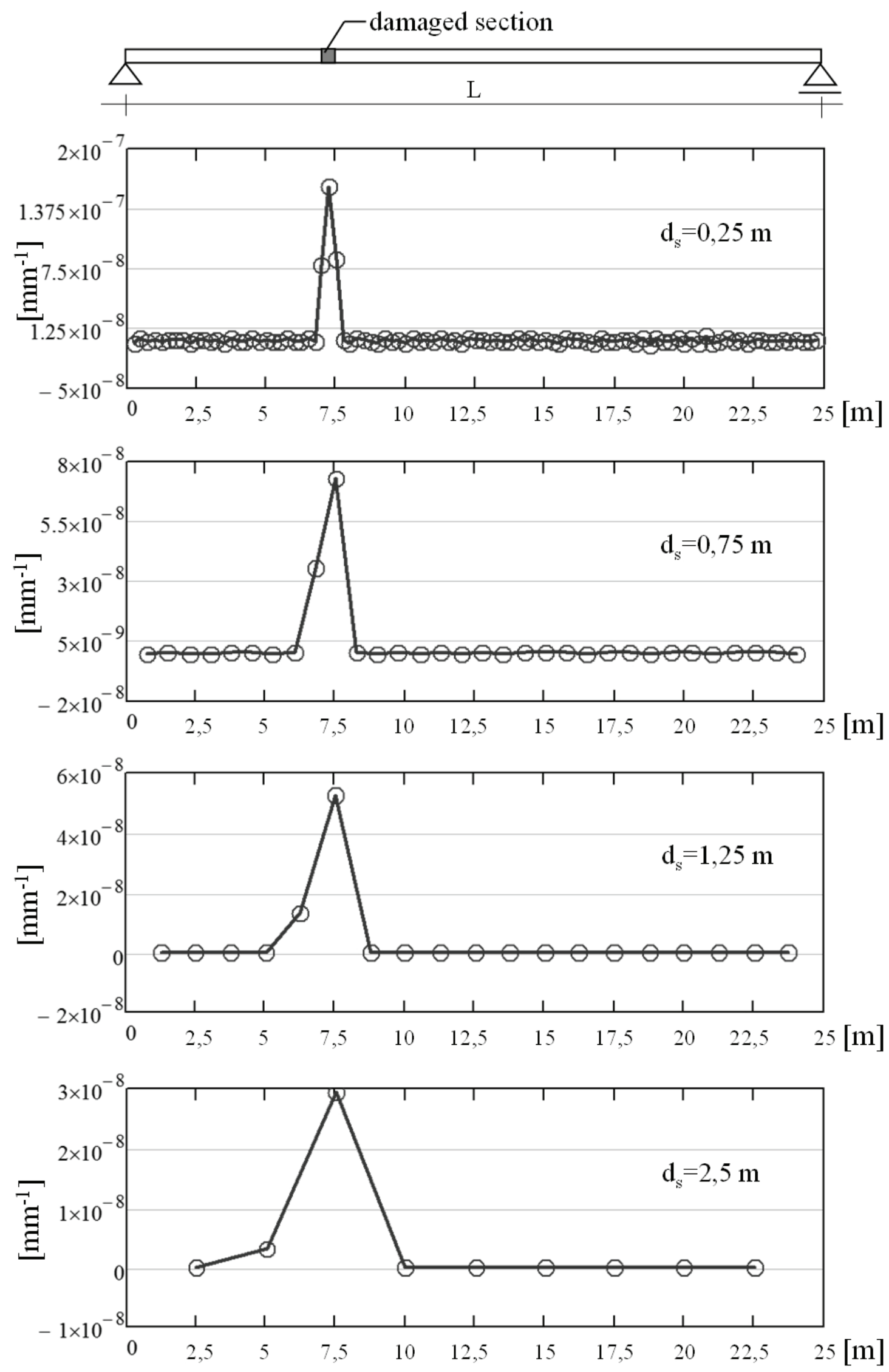

Figure 4: The difference in the curvature of the deflection influence lines for different sampling interval $d_{s}$ 


\section{CONCLUSION}

In the paper, the influence of sampling interval on deflection influence line based damage detection method in beams is investigated. Conducted numerical analysis shows applicability of this method even when small number of sampling point is used.

On-site testing can be carried out using relatively small number of sampling point to detect and roughly locate the damage. Afterwards, the potential damaged location can be tested again with smaller sampling interval or by using other non-destructive technique (such as ultrasound) to determine the damage location more accurately.

\section{REFERENCES}

1) I. Štimac: „Uporaba utjecajnih linija progiba u otkrivanju oštećenja konstrukcija“, Disertacija, Građevinsko-arhitektonski fakultet Sveučilišta u Splitu, Split, 2006, 139 str.

2) I. Štimac, A. Mihanović, I. Kožar: „Uporaba utjecajnih linija progiba za otkrivanje oštećenja na grednim konstrukcijama“, Prvi sabor hrvatskih mostograditelja, Brijunski otoci, 2005, str. 747-754

3) I. Štimac, A. Mihanović, I. Kožar: „Damage Detection from Analysis of Displacement Influence Lines“, International Conference on Bridges, Dubrovnik, 2006, str. 1001-1008

4) I. Štimac, I. Kožar: „Damage Detection from Displacement-in-time Function", 4th Youth Symposium on Experimental Solid Mechanics, Bologna, 2005, pp. 3-4

5) I. Štimac Grandić, D. Grandić, A. Bjelanović: "Comparison of Techniques for Damage Identification Based on Influence Line Approach", Machines, Technologies, Materials, 7, 2011, pp. 9-13

6) I. Choi, et al.: "Development of elastic damage load theorem for damage detection in statically determinate beam", Computer and Structures, 82(29-30), 2004, pp. 2483-2492,.

7) I. Štimac, I. Kožar, A. Mihanović: „Otkrivanje oštećenja greda s pomoću utjecajnih linija progiba“ Građevinar, 59(12), 2007, str. 1053-1066

Paper sent to revision: 07.02.2014.

Paper ready for publication: 15.03.2014. 